\title{
Os Escaravelhos e o Tempo
}

\author{
Marcos Paulo Gomes Gonçalves ${ }^{1}$ \\ ${ }^{1}$ Centro de Ciências Agrarias, Universidade Federal do Piaui, Teresina, PI, Brasil.
}

Recebido em: 8 de Abril de 2017 - Aceito em: 11 de Março de 2020

\begin{abstract}
Resumo
Estudar os fatores temporais na flutuação populacional dos escaravelhos é fundamental para compreensão de sua variação ao longo do ano. Assim, analisou-se relação entre tempo e flutuação populacional de escarabeídeos em Mata de Cocal, no município de Teresina-PI, no período de agosto de 2011 a julho de 2012. Semanalmente, coletaram-se escaravelhos em 12 armadilhas pitfall, sem atrativos. Confirmou-se correlação canônica entre o conjunto do registro da ocorrência mensal da flutuação populacional das espécies de Scarabaeidae e o conjunto dos dados mensais da insolação, da precipitação pluviométrica, da umidade relativa do ar e da temperatura média, com magnitude de 1, Qui-Quadrado igual a 390,15, com 40 graus de liberdade e o correspondente p-valor igual a $<0,0001$. Significativamente $(\mathrm{p}<0,0001)$, houve correlação canônica entre os dados da insolação $(0,31)$, da precipitação pluviométrica $(0,26)$, da umidade $(0,03)$ e da temperatura $(-0,16)$ ao conjunto dos registros da ocorrência mensal da flutuação populacional de escaravelhos. Desse modo, a flutuação populacional de determinadas espécies de escaravelhos, precipuamente, Coprophanaeus jasius $(0,47$; $\mathrm{p}<0,0001)$, Deltochilum sp. $(0,32 ; \mathrm{p}<0,0001)$ e Dichotomius nisus $(0,48 ; \mathrm{p}<0,0001)$, é estacional e condicionada por parâmetros meteorológicos, principalmente, insolação.
\end{abstract}

Palavras-chave: biometeorologia, entomologia, ecologia.

\section{The Scarabs and the Meteorological Conditions}

\begin{abstract}
Study the meteorological factors is important to understand scarabs population dynamics. So this study examined the relationship between meteorological conditions and the scarabeids population fluctuation in Mata de Cocal in TeresinaPI from August 2011 to July 2012. Scarabs were collected weekly in 12 pitfall traps unattractive. It confirmed canonical correlation between the monthly occurrence record in the Scarabaeidae species in the group of monthly data of insolation, pluviometric precipitation, relative humidity and temperature, with a magnitude of 1 , chi-square equal to 390.15 with 40 degrees of freedom and $p$-value corresponding equal to $<0.0001$. Significantly $(\mathrm{p}<0.0001)$, there was canonical correlation between insolation data $(0.31)$, pluviometric precipitation $(0.26)$, humidity $(0.03)$ and temperature $(-0.16)$ in the monthly occurrence record of the scarabeids. In this way the population fluctuation of certain scarabs species, mainly, Coprophanaeus jasius $(0.47 ; \mathrm{p}<0.0001)$, Deltochilum sp. $(0.32 ; \mathrm{p}<0.0001)$ and Dichotomius nisus $(0.48 ; \mathrm{p}<0.0001)$ is governed predominantly by regional variables and their presence is conditioned by meteorological parameters, insolation principally.
\end{abstract}

Keywords: biometeorology, entomology, ecology.

\section{Introdução}

Os insetos da família Scarabaeidae Latreille, 1802, que são conhecidos, popularmente, a depender da região do Brasil, por escaravelhos, besouros, rola-bostas ou peloteiros, sendo essas duas últimas designações em virtude do hábito que algumas espécies desta família têm de rolar bolas de excremento para efetuar postura - são indicadores importantes da qualidade do meio ambiente, devido à ocorrência em quantidade e diversidade de habitats que ocupam.

Costa et al. (2014) consideram que os besouros constituem-se em importantes organismos do ponto de vista econômico e ecológico, por apresentar representantes

Autor de correspondência: Marcos Paulo Gomes Gonçalves. E-mail: mpgg1988@gmail.com. 
que podem ser pragas florestais e agrícolas, inimigos naturais (predadores), decompositores de matéria orgânica e ainda polinizadores, o que torna a ordem alvo de trabalhos de levantamento. Costa (1999) relata a ocorrência de besouros no solo, nas plantas, nas águas de rios, nos riachos e nas praias marinhas. Marinoni e Ganho (2003) e Paiva (2009) estudaram a associação dos escarabeídeos aos fatores bióticos - relação com os vegetais - e aos fatores abióticos - como a sazonalidade com suas características de temperatura, umidade do ar, pluviosidade e fotoperíodo.

Branco (2008) obteve grande número e diversidade de insetos da ordem Coleoptera em área de cana-de-açúcar com fragmentos de vegetação de Mata de Cocal. Identificou 22 famílias, cujos insetos predominantes coletados encontram-se distribuídos na família Scarabaeidae principalmente. Ao estudar a relação dessa família aos dados meteorológicos de área de capim andropogon com fragmento de Mata de Cocal, Paiva (2009) obteve que a flutuação populacional das espécies de escarabeídeos é estacional e condicionada pelas variáveis meteorológicas precipitação pluviométrica e umidade relativa do ar principalmente.

Os escaravelhos, como explica Gomes Gonçalves (2017), como todos os seres vivos estão sujeitos às forças da natureza, assim, pode haver influência que pode inibir ou favorecer o desenvolvimento de determinada espécie. Destarte, o estudo dos fatores temporais na flutuação populacional dos besouros, bem como sua associação com a vegetação, é de fundamental importância para a compreensão da variação que ocorre em sua população.

Por ser um assunto relevante e para complementar a literatura científica acerca das espécies dessa família de insetos quando associados à Mata de Cocal e às variáveis meteorológicas, objetivou-se analisar a relação dos escaravelhos aos fatores temporais em Mata de Cocal: precipitação pluviométrica, insolação, temperatura média e umidade relativa do ar compensada.

\section{Metodologia}

Realizou-se este estudo no Centro de Ciências Agrárias - CCA, no Campus Agrícola do Socopo da Universidade Federal do Piauí- UFPI, na região de Teresina, no período de agosto de 2011 a julho de 2012. Andrade Júnior et al. (2005) descrevem o clima do município de Teresina, com base na classificação de Thornthwaite e Mather (1955), como sendo C1sA'a', caracterizado como subúmido seco, megatérmico, com excedente hídrico moderado no verão e uma concentração de $32,2 \%$ da evapotranspiração potencial no trimestre - setembro, outubro e novembro.

Utilizou-se uma área de vegetação nativa para a amostragem, latitude e longitude respectivas de $5^{\circ} 2^{\prime} 52^{\prime \prime} \mathrm{S}$ e $42^{\circ} 47^{\prime} 11^{\prime \prime}$ O, que apresenta formação vegetal típica de Mata de Cocal. Branco (2008) caracteriza essa formação como uma área de transição entre floresta Amazônica e Cerrado, com predomínio da palmeira coco babaçu (Attalea speciosa Mart. ex Spreng).

Geograficamente essa grande transição concentra-se sobre os estados do Piauí e do Maranhão, porção mais oeste da região Nordeste, amplamente ocupada por formações dicótilo-palmáceas, cf. IBGE (1992). Em termos vegetacionais, forma-se um extenso mosaico com fisionomias tão díspares que se observa em pouco espaço a especialidade da região em ter disseminadas feições com diferentes espécies e estruturas, acompanhadas por variações nos solos e no clima (Santos Filho et al., 2010). Farias e Castro (2004) descrevem o meio norte do Brasil Piauí e Maranhão - como uma extensa zona ecotonal situada entre o subúmido amazônico e o semiárido nordestino.

O solo da área amostrada, com base no Sistema Brasileiro de Classificação de Solos EMBRAPA (2006), é Argissolo Vermelho Amarelo, Distrófico, com textura arenosa média, muito profundo, ácido e com relevo plano.

Para as amostras, utilizou-se de armadilhas de solo, pitfall, sem atrativos, as quais Paiva (2009) e Costa et al. (2014) utilizaram e com as quais se empregam na captura de animais de solo. Obtiveram-se as amostras em três unidades amostrais independentes, chamadas de "estações" localizadas ao nível do solo. Cada estação consistiu de quatro recipientes de plástico, cada qual com capacidade de $500 \mathrm{~mL}$, diâmetro de $10 \mathrm{~cm}$ e altura de $11 \mathrm{~cm}$, os quais receberam uma cobertura de um prato plástico de $20 \mathrm{~cm}$ de diâmetro, suspenso por peças de madeira com aproximadamente $15 \mathrm{~cm}$, para impedir ou diminuir a entrada de água no período das chuvas. Enterraram-se os recipientes com a borda ao nível do solo e em cada um adicionaramse $200 \mathrm{~mL}$ de solução formol 4\% como líquido fixador. Interligaram-se os frascos por anteparos de metal com $100 \mathrm{~cm}$ de comprimento por $20 \mathrm{~cm}$ de altura, com função de guiar os insetos até um dos recipientes da estação, disposta no formato de um Y. Por meio da Fig. 1 (adaptada), observa-se o desenho esquemático da estação.

Havia três estações iguais na área amostrada, dispostas aleatoriamente. Cada estação guardava entre si distância de cerca de $5 \mathrm{~m}$. Obtiveram-se amostras semanais, o que totalizaram 52 amostras no período de agosto de 2011 a julho de 2012. No laboratório de entomologia do Departamento de Fitotecnia do CCA da UFPI, fez-se a triagem e a identificação dos espécimes da ordem Coleoptera, além do depósito do material amostrado para sua preservação, para possíveis estudos futuros.

Obtiveram-se os dados meteorológicos mensais da temperatura média do ar compensada, da umidade relativa do ar compensada, da precipitação pluviométrica e da insolação através da rede do Instituto Nacional de Meteorologia - INMET. A estação meteorológica do INMET da qual são originários os dados meteorológicos obtidos possui latitude e longitude respectivas de $5^{\circ} 2 ' 20,16^{\prime \prime} \mathrm{S}$ e $42^{\circ}$ - 


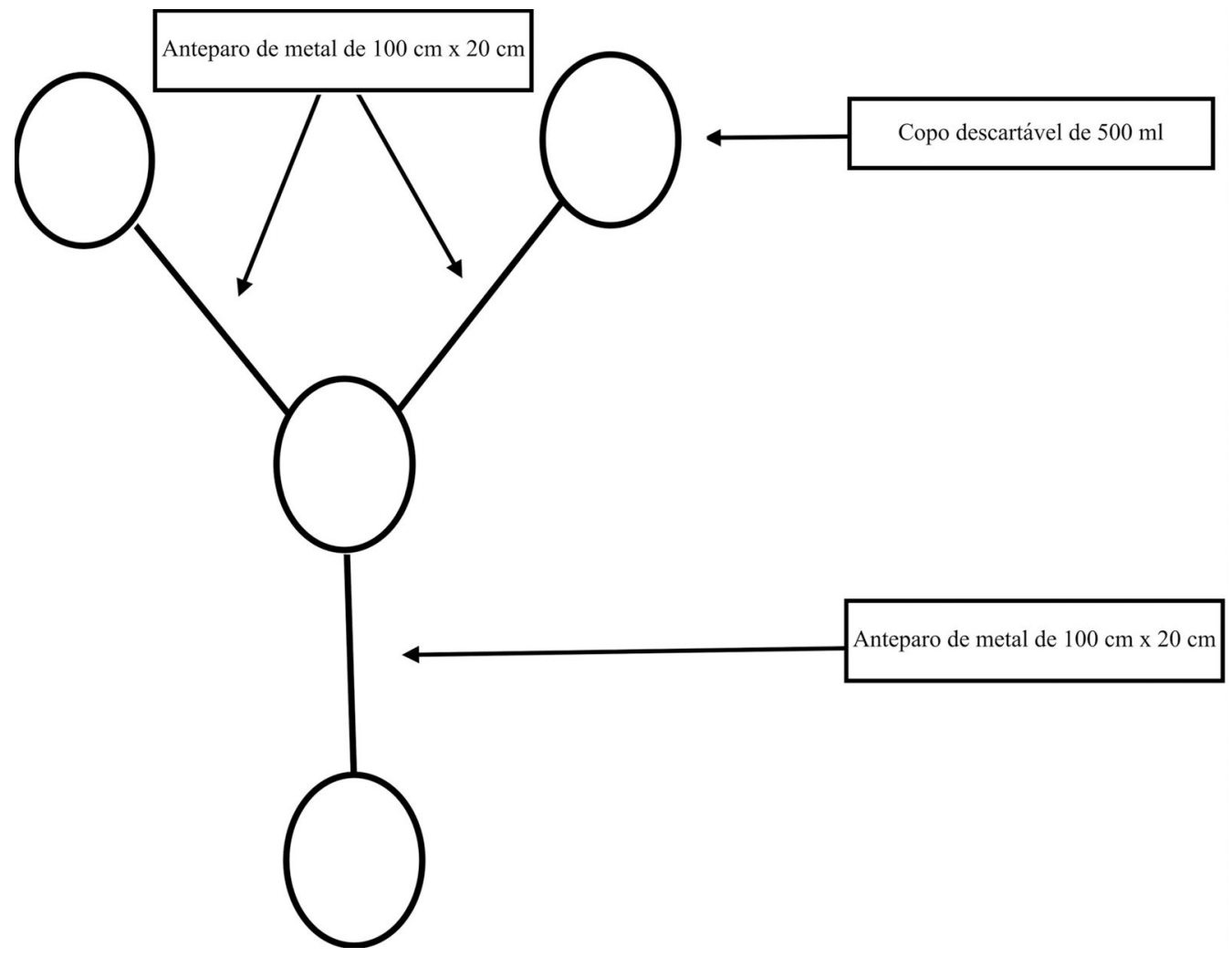

Figura 1 - Desenho esquemático de uma estação para coleta de insetos de solo, pitfall, adaptado.

48'14,77" O e altitude de $75 \mathrm{~m}$. A área de mata nativa em qual se obtiveram as amostras está dentro de um raio de $3 \mathrm{~km}$ da referida estação meteorológica.

Calcularam-se os índices faunísticos: dominância, abundância, frequência e constância, assim como índices de diversidade, variância $\mathrm{H}$ e intervalo de confiança com o software ANAFAU (Moraes et al., 2003). Também, realizou-se correlação pelo método de Pearson entre o registro de ocorrência mensal da flutuação populacional das espécies e os dados mensais das variáveis meteorológicas através do software BIOESTAT versão 5.3 (Ayres, 2007). Posteriormente, realizou-se pelo mesmo software correlação canônica entre o conjunto da ocorrência mensal da flutuação populacional das espécies e o conjunto dos dados meteorológicos mensais.

\section{Resultados e Discussão}

\subsection{Flutuação populacional e medidas faunísticas}

Observa-se, pela Tabela 1, que no período analisado, na Mata de Cocal, amostraram-se 1.121 insetos da família Scarabaeidae, distribuídas em 8 gêneros, sendo 3 espécies indeterminadas para as quais se acrescentou ao lado do gênero a designação sp. e 7 determinadas: Aphodius sp. Illiger, 1798; Ateuches sp. Weber, 1801; Canthidium sp. Erichson, 1847; Canthon sp. 1 Hoffmannsegg, 1817; Can- thon sp. 2 Hoffmannsegg, 1817; Coprophanaeus jasius Olivier, 1789; Deltochilum sp. Eschscholtz, 1822; Deltochilum sp. 1 Eschscholtz, 1822; Dichotomius nisus Olivier, 1789; e Dyscinetus dubius Olivier, 1789. Destacaram-se as espécies Canthidium sp., Canthon sp. 1 e Deltochilum sp. 1 com 395; 327 e 157 espécimes respectivamente. O mesmo que 35,$24 ; 29,17$ e $14 \%$ do total de escaravelhos amostrados respectivamente. As outras 7 espécies, quando juntas, apresentaram 242 indivíduos, os quais representa $21,57 \%$ do total de escarabeídeos registrados.

A flutuação populacional de besouros variou do mínimo de 1 espécime, setembro de 2011, ao máximo de 217 besouros, março de 2012. Essa variação representa em torno de $0,09 \%$ no mínimo e $19,36 \%$ no máximo da população total dos escaravelhos amostrados durante o referido período. De novembro de 2011 a maio de 2012, amostraram-se 1.078 espécimes, cerca de $96,16 \%$ do total de besouros identificados, enquanto, nos meses de agosto a outubro de 2011 e de junho a julho de 2012, identificaramse 43 espécimes, cerca de 3,84\% do total de escarabeídeos amostrados.

Segundo Gomes Gonçalves (2017), o pico populacional de determinada família ou de determinada espécie ocorre quando o conjunto de mecanismos homeostáticos da natureza, em relação à própria família ou à própria espécie, tanto intrínsecos - internos - quanto extrínsecos - 
Tabela 1 - Registros da ocorrência mensal da flutuação populacional de escarabeídeos amostrados em área de Mata de Cocal do município de Teresina-PI, no período de agosto de 2011 a julho de 2012.

\begin{tabular}{|c|c|c|c|c|c|c|c|c|c|c|c|c|c|}
\hline \multirow[t]{2}{*}{ Espécies } & \multicolumn{5}{|c|}{2011} & \multicolumn{7}{|c|}{2012} & \multirow[t]{2}{*}{ Total } \\
\hline & Ago. & Set. & Out. & Nov. & Dez. & Jan. & Fev. & Mar. & Abr. & Mai. & Jun. & Jul. & \\
\hline Aphodius sp. & - & - & - & - & - & 3 & 5 & - & 20 & 21 & - & - & 49 \\
\hline Ateuchus sp. & - & - & - & - & - & - & - & - & 2 & - & - & - & 2 \\
\hline Canthidium sp. & - & - & - & 21 & 87 & 66 & 43 & 53 & 31 & 87 & 5 & 2 & 395 \\
\hline Canthon sp. 1 & - & - & - & 46 & 67 & 68 & 12 & 102 & 15 & 6 & 11 & - & 327 \\
\hline Canthon sp. 2 & - & - & - & 5 & 14 & - & 33 & - & - & - & 10 & - & 62 \\
\hline Coprophanaeus jasius & - & - & - & - & 1 & - & - & 3 & - & - & - & - & 4 \\
\hline Deltochilum sp. 1 & - & 1 & 2 & 26 & 5 & 38 & 11 & 5 & 1 & 68 & - & - & 157 \\
\hline Deltochilum sp. & 8 & - & - & 3 & 1 & 20 & 16 & 39 & 2 & - & - & - & 89 \\
\hline Dichotomius nisus & - & - & - & - & - & 2 & - & 15 & - & 12 & 4 & - & 33 \\
\hline Dyscinetus dubius & - & - & - & 3 & - & - & - & - & - & - & - & - & 3 \\
\hline Total & 8 & 1 & 2 & 104 & 175 & 197 & 120 & 217 & 71 & 194 & 30 & 2 & 1121 \\
\hline
\end{tabular}

externos - é favorável ao seu desenvolvimento em um determinado habitat, em um determinado período de tempo. Os mecanismos intrínsecos dependem dos próprios integrantes da população, como é o caso da competição intraespecífica, enquanto os extrínsecos dependem da participação de alguma coisa fora da própria população, como a competição interespecífica, restrições de alimento e de espaço, os intemperismos, o parasitismo, o predatismo e as variações meteorológicas. Desse modo, o mês e o período com as condições homeostáticas ambientais mais favoráveis à comunidade de escaravelhos estudada foram março de 2012 e novembro de 2011 a maio de 2012, enquanto que os meses de setembro de 2011 e junho e julho de 2012 tiveram as condições menos favoráveis à população de escarabeídeos.

Pela Tabela 2, observa-se que as espécies Canthidium sp. e Canthon sp. 1 foram aquelas que obtiveram os maiores valores em todos os índices faunísticos calculados: abundância, dominância, frequência e constância. Elas foram superdominantes, constantes, superfrequentes e superabundantes. Obteve-se, ainda, para a comunidade Scarabaeidae, com intervalo de confiança de $[\mathrm{P}=0,05$ $(1,560491 ; 1,567743)]$, índice de diversidade ShannonWeaner de 1,5641, índice de riqueza Margalef de 1,1688 e índice de equitabilidade de 0,7522. O índice de diversidade mede o grau de incerteza em prever a que espécie pertencerá um espécime tomado ao acaso de uma amostra com $\mathrm{S}$ espécies e $\mathrm{N}$ espécimes, no presente caso, 10 e 1.121 respectivamente. Quanto menor o valor do índice de Shannon, menor o grau de incerteza e, portanto, menor a adversidade da amostra. A estimativa de riqueza do índice de Margalef consiste na distribuição numérica dos indivíduos das diferentes espécies em função do número total de espécimes existentes na amostra. Valores abaixo de 2, como o do presente estudo, são indicadores de baixa biodiversidade de acordo com Lexerød and Eid (2006). O índice de equitabilidade, que varia entre 0 e 1 , indica quanto da diversidade observada se aproxima da diversidade máxima, a qual ocorre quando os indivíduos estão distribuídos de maneira igual entre as espécies. Quanto mais próximo de 1 , mais uniformemente, estão distribuídos os indivíduos na comunidade estudada. Para Miller Jr (2008), a diversidade apresenta dois componentes: a riqueza da espécie observada e a equitabilidade. Conforme Miller Jr (2008), uma riqueza elevada de espécies associa-se a uma baixa equitatividade de espécies normalmente. Verificou-se essa relação inversamente proporcional no presente trabalho.

Tabela 2 - Análise faunística de espécies de escarabeídeos amostrados em área de Mata de Cocal do município de Teresina-PI, no período de agosto de 2011 a julho de 2012.

\begin{tabular}{lcccc}
\hline Espécies & Dominância & Abundância & Frequência & Constância \\
\hline Aphodius sp. & $\mathrm{D} *$ & $\mathrm{c}$ & $\mathrm{F}$ & $\mathrm{Y}$ \\
Ateuchus sp. & $\mathrm{ND}$ & $\mathrm{d}$ & $\mathrm{PF}$ & $\mathrm{Z}$ \\
Canthidium sp. & SD & sa & SF & W \\
Canthon sp. 1 & SD & sa & SF & W \\
Canthon sp. 2 & $\mathrm{D}$ & $\mathrm{c}$ & $\mathrm{F}$ & $\mathrm{Y}$ \\
Coprophanaeus & $\mathrm{ND}$ & $\mathrm{d}$ & $\mathrm{PF}$ & $\mathrm{Z}$ \\
jasius & & & & \\
Deltochilum sp. 1 & $\mathrm{D}$ & $\mathrm{ma}$ & $\mathrm{MF}$ & $\mathrm{Y}$ \\
Deltochilum sp. & $\mathrm{D}$ & $\mathrm{a}$ & $\mathrm{MF}$ & $\mathrm{Y}$ \\
Dichotomius nisus & $\mathrm{D}$ & $\mathrm{c}$ & $\mathrm{F}$ & $\mathrm{Y}$ \\
Dyscinetus dubius & $\mathrm{ND}$ & $\mathrm{d}$ & $\mathrm{PF}$ & $\mathrm{Z}$ \\
\hline
\end{tabular}

Índice de Diversidade (Shannon-Weaner) $=>\mathrm{H}=1,5641$; Intervalo de Confiança de H $(\mathrm{P}=0,05)=>[1,560491 ; 1,567743]$; Índice de Riqueza (Margalef) $\Rightarrow$ ALFA $=1,1688$; Índice de Uniformidade ou Equitabilidade $=>\mathrm{E}=0,7522 ; * \mathrm{D}=$ dominante; $\mathrm{ND}=$ não dominante; $\mathrm{SD}=$ superdominante; $\mathrm{SF}=$ superfrequente; $\mathrm{MF}=$ muito frequente; $\mathrm{PF}=$ pouco frequente; $\mathrm{W}=$ constante; $\mathrm{Y}=$ acessória; $\mathrm{Z}=$ acidental; $\mathrm{r}=$ rara; $\mathrm{c}=\mathrm{co}-$ mum $; \mathrm{ma}=$ muito abundante; as $=$ superabundante $\mathrm{d}=$ dispersa . 
Para a comparar os dados da predominância, da quantidade e do número de espécies identificadas do presente trabalho com os de outras localidades da região meio norte do Brasil é necessário que se citem estudos já desenvolvidos.

No município de União-PI, em área de cana-de-açúcar com fragmentos de vegetação de Mata de Cocal, por meio de armadilha luminosa, modelo "Luiz de Queiroz", Branco (2008) obteve 9.892 escaravelhos distribuídos em 25 espécies, dentre as quais predominaram: Astaena sp. com 3.313 besouros e Cyclocephala sp. 2 com 2.415 espécimes. Em Teresina-PI, em área de capim Andropogon com fragmento de Mata de Cocal, por meio de 10 armadilhas de solo, sem atrativos, Paiva (2009) coletou 355 escarabeídeos distribuídos em 15 espécies, em quais Canthidium sp. 2, Canthon sp. 2 e Canthon sp. 6 com 85, 77 e 62 indivíduos respectivamente foram as espécies com maior população e com os maiores índices faunísticos, portanto predominantes. No município de Nazária-PI, em área de Mata de Cocal, por meio de armadilhas de solo com iscas e sem iscas, Carvalho (2013), identificou 3.393 besouros distribuídos em 31 espécies de escaravelhos, sendo as predominantes e com o maior número de indivíduos: Dichotomius sp. com 649 escarabeídeos e Ontherus appendiculatus Mannerheim, 1829, com 570 escaravelhos.

A diferença dos dados da predominância, da quantidade e do número de espécies identificadas de Scarabaeidae do presente estudo em comparação com os dos demais estudos citados pode ser explicada em decorrência da utilização de armadilhas diferentes, do seu número e quantidade de amostras obtidas, além da relação dos insetos aos fatores bióticos - relação com os vegetais; competições intra e interespecíficas; diversidade de mamíferos, os quais possibilitam maior ou menor disponibilidade e diversidade de excrementos - e aos fatores abióticos como a sazonalidade com suas características de temperatura, umidade do ar, pluviosidade e fotoperíodo; além das condições edáficas do solo; dentre outros fatores.

\subsection{Escaravelhos e variáveis meteorológicas}

\subsubsection{Dados meteorológicos}

Ao longo do estudo, houve média de insolação de $8,4 \mathrm{~h} \cdot \mathrm{d}^{-1}$, umidade relativa média do ar compensada de $72,4 \%$, temperatura média do ar compensada diária de $27,4{ }^{\circ} \mathrm{C}$ e $1.218,9 \mathrm{~mm}$ de precipitação pluviométrica no município de Teresina. Quando se compara esses valores à normal climatológica de 1980 a 2009 calculada por Bastos e Andrade Júnior (2011) - que teve insolação média de $7,8 \mathrm{~h} . \mathrm{d}^{-1}$, umidade relativa do ar de $69,8 \%$, temperatura média do ar de $28,2{ }^{\circ} \mathrm{C}$ e $1.351,9 \mathrm{~mm}$ de precipitação total anual -, verifica-se que a insolação e a umidade foram superiores, enquanto a precipitação e a temperatura, infe- riores. Consta o registro dos dados meteorológicos mensais do período na Tabela 3 .

\subsubsection{Relação entre os escaravelhos e as variáveis meteorológicas}

Os besouros como todos os seres vivos estão sujeitos às forças da natureza, portanto há influência relevante de forma que pode inibir ou favorecer o desenvolvimento de determinada espécie. Destarte, o estudo dos fatores temporais na flutuação populacional dos besouros é de fundamental importância para a compreensão da variação que ocorre em sua população.

Para averiguação e compreensão dessa associação em Mata de Cocal, correlacionaram-se os registros de ocorrência mensal da flutuação populacional das espécies de coleópteros e os dados mensais meteorológicos. As espécies Canthidium sp., Canthon sp. 2, Deltochilum sp. e Dichotomius nisus associaram, significativamente, com $\mathrm{p}<0,10$ e 10 graus de liberdade, ao menos, a uma das variáveis meteorológicas estudadas, como se observa pela Tabela 4. Duas espécies - Canthon sp. $2(-0,56 ; \mathrm{p}<0,10)$ e Deltochilum sp. $(-0,51 ; \mathrm{p}<0,10)$ - associaram-se à insolação negativamente; três - Canthidium sp. $(0,53$; $\mathrm{p}<0,10)$, Deltochilum sp. $(0,60 ; \mathrm{p}<0,05)$ e Dichotomius nisus $(0,51 ; \mathrm{p}<0,10)$ - associaram-se positivamente à umidade; e uma - Deltochilum sp. - associou-se, positivamente, com $\mathrm{p}<0,05$, à precipitação pluviométrica $(0,69)$ e à temperatura $(0,57)$. As espécies Aphodius sp., Ateuches sp., Canthon sp. 1, Coprophanaeus jasius, Deltochilum sp. 1 e Dyscinetus dubius., com p-valor igual a $>0,10$, não obtiveram associação significativa. Conforme os Figs. 2, 3, 4 e 5, nota-se que somente a espécie

Tabela 3 - Dados meteorológicos (Insolação, Umidade relativa média do ar compensada, Precipitação Pluviométrica e Temperatura média do ar compensada) de 01 de Agosto de 2011 a 31 de Julho de 2012, no município de Teresina-Piauí.

\begin{tabular}{cccccc}
\hline Ano & Meses & $\begin{array}{c}\text { Insolação } \\
\left(\mathrm{h.d}^{-1}\right)\end{array}$ & $\begin{array}{c}\text { Umidade } \\
\text { relativa } \\
(\%)\end{array}$ & $\begin{array}{c}\text { Precipitação } \\
(\mathrm{mm})\end{array}$ & $\begin{array}{c}\text { Temperatura } \\
\text { média }\left({ }^{\circ} \mathrm{C}\right)\end{array}$ \\
\hline \multirow{2}{*}{2011} & Agosto & 10,1 & 65,4 & 10,8 & 27,2 \\
& Setembro & 10,3 & 58,1 & 0,6 & 28,5 \\
& Outubro & 8,8 & 66,1 & 167,6 & 28,6 \\
& Novembro & 7,8 & 74,8 & 124,6 & 27,4 \\
& Dezembro & 8,6 & 68,2 & 23,4 & 28,3 \\
& Janeiro & 6,4 & 75,7 & 133,1 & 27,1 \\
& Fevereiro & 5,6 & 83,4 & 317,1 & 26,2 \\
& Março & 7,4 & 85 & 264 & 26,3 \\
& Abril & 7,7 & 82,5 & 121 & 26,7 \\
& Maio & 9,3 & 77,3 & 31,3 & 27,2 \\
& Junho & 8,8 & 72,7 & 25,4 & 27,2 \\
& Julho & 10 & 60,8 & 0 & 27,5 \\
\hline
\end{tabular}

Fonte: Dados da Rede do INMET. 
Tabela 4 - Correlação entre os registros de ocorrência mensal da flutuação populacional de escarabeídeos e os dados meteorológicos mensais em área de Mata de Cocal, no município de Teresina-PI, de agosto de 2011 a julho de 2012.

\begin{tabular}{|c|c|c|c|c|c|c|c|c|}
\hline & \multicolumn{2}{|c|}{ Insolação } & \multicolumn{2}{|c|}{ Umidade } & \multicolumn{2}{|c|}{ Precipitação } & \multicolumn{2}{|c|}{ Temperatura } \\
\hline & (r) & p- valor & (r) & $\mathrm{p}$ - valor & (r) & $\mathrm{p}$ - valor & (r) & p- valo \\
\hline \multicolumn{9}{|l|}{ Espécies } \\
\hline Canthidium sp. & $-0,40$ & ns* & $\mathbf{0 , 5 3}$ & $<0,10$ & 0,19 & $\mathrm{~ns}$ & $-0,15$ & ns \\
\hline Canthon sp. 2 & $-0,56$ & $<0,10$ & 0,32 & ns & 0,46 & $\mathrm{~ns}$ & $-0,23$ & ns \\
\hline Deltochilum sp. & $-0,51$ & $<0,10$ & 0,60 & $<0,05$ & $\mathbf{0 , 6 9}$ & $<0,05$ & $-0,57$ & $<0,05$ \\
\hline Dichotomius nisus & $-0,05$ & ns & 0,51 & $<0,10$ & 0,22 & $\mathrm{~ns}$ & $-0,35$ & ns \\
\hline
\end{tabular}

$\mathrm{N}=12 ; \mathrm{GL}=10 ; * \mathrm{~ns}=$ não significativo.

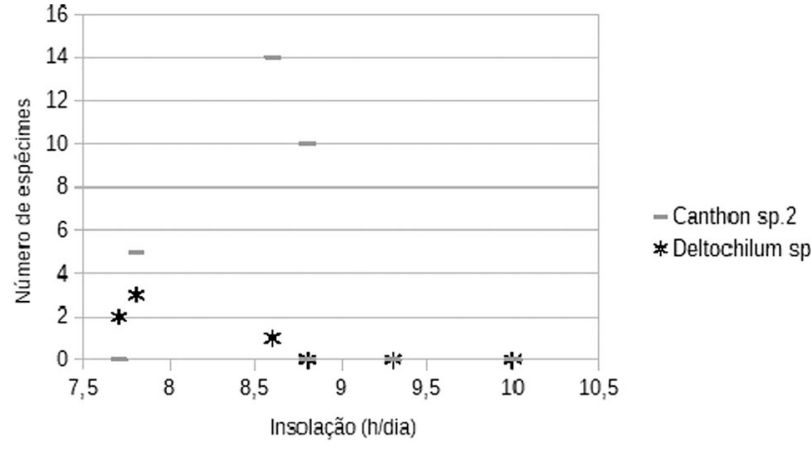

Figura 2 - Diagrama de dispersão dos dados diários mensais da insolação versus o registro da ocorrência mensal da flutuação populacional de escarabeídeos.

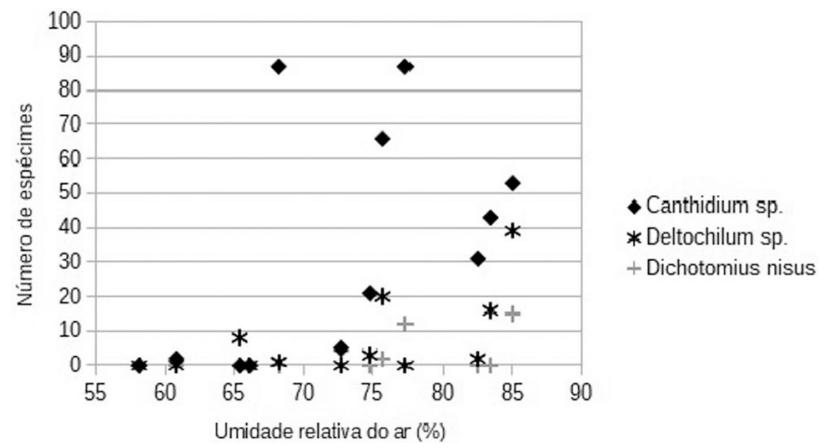

Figura 3 - Diagrama de dispersão dos dados mensais da umidade relativa média do ar compensada versus o registro da ocorrência mensal da flutuação populacional de escarabeídeos.

Deltochilum sp. associou-se a todas as variáveis meteorológicas significativamente.

Realizou-se correlação canônica entre o registro da ocorrência mensal das espécies de escaravelhos com o conjunto dos dados meteorológicos relativos à insolação, à umidade, à precipitação pluviométrica e à temperatura. Observam-se as correlações canônicas e os autovalores pelas Tabelas 5 e 6 . A correlação entre o par das variáveis canônicas, também denominado R Canônico, foi igual a 1 , o qual representa a melhor correlação possível entre qualquer combinação linear dos dados meteorológicos mensais

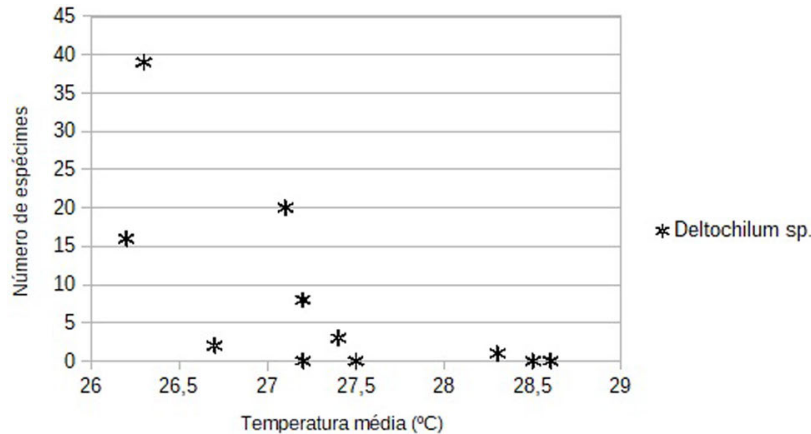

Figura 4 - Diagrama de dispersão dos dados mensais da temperatura relativa média do ar compensada versus o registro da ocorrência mensal da flutuação populacional de escarabeídeos.

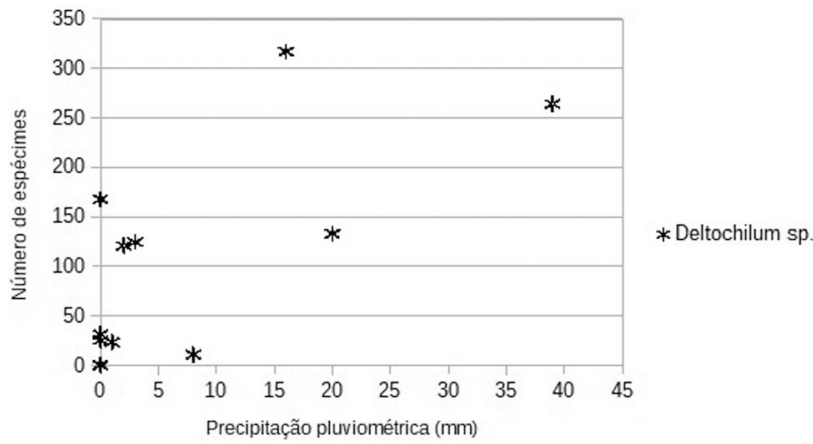

Figura 5 - Diagrama de dispersão dos dados mensais da precipitação pluviométrica versus o registro da ocorrência mensal da flutuação populacional de escarabeídeos.

com os registros da ocorrência mensal dos espécimes das famílias de coleópteros. A estatística R Canônica expressa a magnitude do relacionamento entre os conjuntos de variáveis.

Confirmou-se associação entre os conjuntos de variáveis registro da ocorrência mensal da flutuação populacional das espécies de escarabeídeos e os dados meteorológicos mensais, pelo Qui-Quadrado $\left(\chi^{2}\right)$ igual a 390,15, com 40 graus de liberdade e o correspondente p-valor igual a $<0,0001$, que é muito significativo. Significativamente, $\mathrm{p}<0,0001$, em relação ao conjunto dos dados 
Tabela 5 - Correlação canônica entre os registros da ocorrência mensal da flutuação populacional de escarabeídeos e o conjunto dos dados mensais das variáveis meteorológicas $(\mathrm{U})$.

\begin{tabular}{cccccccccccc}
\hline & A* & B & C & D & E & F & G & J & & & I \\
\hline$U$ & $-0,01$ & $-0,13$ & $-0,21$ & $-0,10$ & $-0,23$ & $\mathbf{0 , 4 7}$ & $-0,14$ & $\mathbf{0 , 3 2}$ & $\mathbf{0 , 4 8}$ & $-0,20$ \\
\hline
\end{tabular}

$\mathrm{R}$ canônico $=1 ; \mathrm{R}^{2}$ canônico $=1 ; \chi^{2}=390,15 ; \mathrm{GL}=40 ; \mathrm{p}$-valor $<0,0001 ; * \mathrm{~A}=$ Aphodius $\mathrm{sp}$; $\mathrm{B}=$ Ateuches $\mathrm{sp}$; $\mathrm{C}=$ Canthidium $\mathrm{sp}$; $\mathrm{D}=$ Canthon $\mathrm{sp}$. 1 ; $\mathrm{E}=$ Canthon sp. $2 ; \mathrm{F}=$ Coprophanaeus jasius $; \mathrm{G}=$ Deltochilum $\mathrm{sp} .1 ; \mathrm{H}=$ Deltochilum $\mathrm{sp}$; $\mathrm{I}=$ Dichotomius nisus $; \mathrm{J}=$ Dyscinetus dubius.

Tabela 6 - Correlação canônica entre os dados mensais das variáveis meteorológicas e o conjunto dos registros da ocorrência mensal da flutuação populacional de escarabeídeos (V).

\begin{tabular}{ccccc}
\hline & Insolação $\left({\left.\mathrm{h} . \mathrm{d}^{-1}\right)}\right.$ & Umidade relativa do ar $(\%)$ & Precipitação $(\mathrm{mm})$ & Temperatura média $\left({ }^{\circ} \mathrm{C}\right)$ \\
\hline $\mathrm{V}$ & $\mathbf{0 , 3 1}$ & 0,03 & 0,26 & $-0,16$ \\
\hline $\mathrm{R}$ & & & \\
\hline
\end{tabular}

$\mathrm{R}$ canônico $=1 ; \mathrm{R}^{2}$ canônico $=1 ; \chi^{2}=390,15 ; \mathrm{GL}=40 ; \mathrm{p}$-valor $<0,0001$.

mensais das variáveis meteorológicas, houve maiores associações para as espécies Coprophanaeus jasius $(0,47)$, Deltochilum sp. $(0,32)$ e Dichotomius nisus $(0,48)$, as quais foram as únicas que se associaram positivamente ao conjunto das variáveis citadas.

Como os insetos são animais pecilotérmicos, ou seja, não possuem sistema de termorregulação, a temperatura ambiente é um fator regulador de sua temperatura interna. Rodrigues (2004) aponta que a temperatura age nos insetos reduzindo a taxa metabólica diretamente, o que interfere no seu desenvolvimento - fase de ovo, larva e pupa - e no seu comportamento. Assim, Rodrigues (2004) considera que quando a temperatura ambiental é favorável, os insetos menores são beneficiados pela fácil troca de calor com o ambiente, tendo, também, atividade respiratória e circulatória mais eficientes, atividade metabólica mais intensa e maior capacidade de aproveitamento dos recursos alimentares. Gallo et al. (2002) descrevem que, em geral, para os insetos, a temperatura ótima para o desenvolvimento mais rápido e para o maior número de descendentes, está próxima de $25{ }^{\circ} \mathrm{C}$ e consideram que a faixa ótima para o desenvolvimento da maioria dos insetos encontra-se entre 15 e $38{ }^{\circ} \mathrm{C}$. Em área de Mata de Cocal, houve associação negativa significativa $(-0,16 ; p<0,0001)$ entre os dados mensais da temperatura média do ar compensada e o conjunto dos registros da ocorrência mensal da flutuação populacional dos besouros.

Rodrigues (2004) considera que alguns insetos necessitam, como as plantas, de um determinado número de horas de sol para completarem seu desenvolvimento, pois as horas interferem na fertilidade e na longevidade. Basset (1992), citado por Gonçalves e Louzada (2005), considera que a insolação, ao lado da umidade e da temperatura, é determinante para a distribuição da riqueza faunística dos insetos. Os dados mensais da média diária de insolação associaram-se ao conjunto dos registros de ocorrência mensal dos escarabeídeos positivamente $(0,31$; $\mathrm{p}<0,0001)$. Entre as variáveis, a insolação teve a maior associação.
Rodrigues (2004) aponta que a porção de água contida no corpo dos insetos varia entre 70 a $90 \%$ e que essa variação depende do tipo de alimento que consomem e do ambiente em que vivem. A umidade relativa do ar está relacionada de forma direta com a exposição dos insetos ou seu resguarde, o baixo teor de umidade pode afetar a fisiologia, longevidade, desenvolvimento e oviposição dos insetos (Gullan e Cranston, 2007). Gallo et al. (2002) descrevem que a faixa favorável para a maioria dos insetos para ter maior longevidade, fecundidade e velocidade de desenvolvimento varia entre 40 a $80 \%$. Houve associação positiva $(0,03 ; p<0,0001)$ entre os dados mensais da umidade relativa do ar compensada e o conjunto dos registros da ocorrência mensal da flutuação populacional de escaravelhos. Entre as variáveis, a umidade relativa do ar teve a menor associação.

A precipitação pluviométrica pode interferir também indiretamente nos insetos. Marinoni e Ganho (2003), em áreas com diferentes graus de antropização e de sucessão vegetal, em Ponta Grossa-PR, verificaram que a sazonalidade dos insetos é relacionada ao período chuvoso, pois há ocorrência de maior disponibilidade de recursos alimentares, o que proporciona um pico populacional elevado. No entanto, deve-se observar que o excesso hídrico pode ser prejudicial às plantas, porquanto lhes pode proporcionar estresse hídrico, bem como ao habitat, solo, de alguns insetos que pode ficar encharcado. Os dados mensais da precipitação pluviométrica associaram-se ao conjunto dos registros da ocorrência mensal da flutuação populacional das espécies positivamente $(0,26$; $\mathrm{p}<0,0001)$.

Há estudos em que houve o maior registro dos espécimes amostrados na estação chuvosa e há outros em que não houve diferença significativa entre a estação chuvosa e a estação seca. Por exemplo, em um fragmento de Mata Atlântica na Reserva Ecológica de Gurjaú-PE, Santos (2005) obteve $71,5 \%$ do total dos espécimes amostrados na estação chuvosa (maio e julho de 2003) e $28,5 \%$ do total dos besouros amostrados na estação seca (outubro e novembro de 2003), enquanto, em fragmentos de floresta 
serrana de brejo de altitude no estado de Paraíba, Neves (2006) obteve $53 \%$ do total dos coleópteros amostrados na estação chuvosa de abril a julho de 2005 e $47 \%$ do total de besouros coletados na estação seca de novembro de 2004 a fevereiro de 2005.

Rodrigues (1989) aponta que poucas espécies de besouros coprófagos sobrevivem em áreas com precipitação média anual inferior a $250 \mathrm{~mm}$ e que o número de indivíduos aumenta apenas no início das primeiras chuvas e com a elevação da temperatura do ar. Corroborando com esse entendimento, Campiglia (2002) e Paiva (2009) concluíram que, em pastagens, a flutuação populacional da comunidade de escarabeídeos é regida predominantemente pelas variáveis macroclimáticas da região e que a presença destes besouros é estacional e condicionada por parâmetros temporais, correlacionando, negativamente, à temperatura média do ar compensada e, positivamente, à umidade relativa média do ar compensada e à precipitação pluviométrica. Em área de Mata de cocal, mesmo com valores canônicos fracos das associações, observou-se esse comportamento também. Provavelmente, a presença de árvores proporcionou condições microtemporais que favoreceram que determinadas espécies de escaravelhos não se tornassem tão dependentes das variáveis meteorológicas.

\subsection{Nicho ecológico da família Scarabaeidae}

Os indivíduos das espécies identificadas ocupam posição funcional ou posição biológica dentro do ecossistema em que estão inseridos. Isso compreende o que os espécimes representam no quadro geral do ecossistema, pelo que eles fazem e como fazem.

Os insetos da família Scarabaeidae são detritívoros, cuja alimentação se baseia em massa fecal de mamíferos, coprofagia; restos de animais mortos, necrofagia; e frutos em decomposição, saprofagia, (Halffter e Matthews, 1966). No ato de transportar e enterrar a maior parte dos excrementos dos quais se utilizam, acarretam a aceleração do processo de ciclagem dos nutrientes, tornando-o mais eficiente, consequentemente, aumentam a fertilidade do solo (Koller et al., 1997).

Dependendo do modo que os escaravelhos transportam o excremento que se utilizarão, Halffter (1991) classificá-los em três grupos:

a. roladores ou telecoprídeos: rolam a bola de excremento de onde se encontram no solo até o seu ninho;

b. escavadores ou paracoprídeos: transportam o alimento para o interior do solo, escavando túneis sob ou do lado do excremento;

c. residentes ou endocoprídeos: utilizam o excremento no local, não o transportando.

Esses modos diferentes de se transportar o excremento diminuem ou até mesmo evitam a competição entre as espécies pelo alimento. Essa relação é de grande importância pelo fato de contribuir para o aumento do número de espécies na comunidade e por proteger o alimento das adversidades do tempo.

Dessa maneira, conforme Nichols et al. (2008) e Slade et al. (2011), os escarabeídeos são importantes nos ecossistemas por promover a remoção e reentrada de matéria orgânica no solo, auxiliando na reciclagem de nutrientes e melhorando a aeração do solo, podendo, ainda, atuar na regulação de populações de outros artrópodes, inclusive pragas.

Os escarabeídeos, de acordo com Favila e Halffter (1997), são bastante específicos quando se refere ao seu habitat, sendo essa característica fundamental quando se analisa a diversidade de espécies dessa família em diferentes ambientes. Segundo Gomes Gonçalves (2017), dado que cada espécie pode está associada a diversos fatores como, o clima, o solo, o tipo de vegetação, entre outros, os processos de desmatamento das áreas de mata nativa, podem levar à perda de espécies, causando alterações em sua comunidade.

Conforme Gomes Gonçalves (2017), todas as entidades físicas e biológicas de um determinado ecossistema formam um único sistema integrante unificado e complexo. Como visto, há vinculação profunda, direta e essencial dos escaravelhos com os processos ecológicos do ecossistema em que estão inseridos.

Dada essa importância, faz-se necessária a permanência deles no ambiente em que estão, para tanto deve-se haver a manutenção das condições meteorológicas relativas à insolação, precipitação, temperatura e umidade, bem como a conservação da Mata de Cocal.

\section{Considerações Finais}

Constatou-se que o melhor período para maximização amostral, para coleta de escaravelhos, em Mata de Cocal, por meio de armadilhas de solo sem atrativos em estações, é no período de novembro a maio, sendo o mês de março com as melhores condições ambientais homeostáticas para a comunidade de escarabeídeos. Verificou-se predominância das espécies Canthidium sp. e Canthon sp. 1.

Evidenciou-se que o registro da flutuação populacional das espécies Canthidium sp., Canthon sp. 2, Deltochilum sp. e Dichotomius nisus é afetado ao longo do ano, porque as mesmas estão associadas, ao menos, a uma das variáveis: insolação, precipitação pluviométrica, temperatura média e umidade relativa média do ar compensada. Somente, a espécie Deltochilum sp. associou-se a todas as variáveis meteorológicas.

Confirmou-se correlação canônica entre os conjuntos de variáveis: registro da ocorrência mensal da flutuação populacional de espécies de escarabeídeos e os dados meteorológicos mensais. Também, houve correlação canônica positiva entre os dados da insolação, da precipitação pluviométrica e da umidade e negativa da temperatura ao conjunto dos registros de ocorrência mensal da 
flutuação populacional das espécies de Scarabaeidae. As maiores associações entre o conjunto dos dados meteorológico foram das espécies Coprophanaeus jasius, Deltochilum sp. e Dichotomius nisus.

Por fim, como o presente trabalho mostra que a flutuação populacional de determinadas espécies de escaravelhos, precipuamente, Coprophanaeus jasius, Deltochilum sp. e Dichotomius nisus, é estacional e condicionada por parâmetros meteorológicos, principalmente, insolação, se torna importante como parâmetro para uma primeira descrição para posteriores trabalhos de levantamento, quando associados à Mata de Cocal e às variáveis meteorológicas.

\section{Referências}

ANDRADE JÚNIOR, A.S.; BASTOS, E.A.; BARROS, A.H.C.; SILVA, C.O.; GOMES, A.A.N. et al. Classificação climática e regionalização do semiárido do Estado do Piauí sob cenários pluviométricos distintos. Revista Ciência Agronômica, v. 36, n. 2, p. 143-151, 2005.

AYRES, M.; AYRES JR., M.; AYRES, D.L.; DOS SANTOS, A.S. et al. BioEstat: Aplicações Estatísticas nas Áreas das Ciências Biológicas e Médicas. Publicações Avulsas Mamirauá, 2007.

BASSET, Y. Host specificity of arboreal and free-living insect herbivores in rain forests. Biological Journal of the Linnean Society, v. 47, n. 2, p. 115-133, 1992.

BASTOS, E.A.; ANDRADE JÚNIOR, A.S. Boletim agrometeorológico de 2010 para o município de Teresina, PI. Embrapa Meio Norte série documentos-210, 2011.

BRANCO, R.T.P.C. Entomofauna Associada à Cultura da Cana-de-Açúcar no Município de União - Piauí - Brasil. Dissertação de Mestrado em Agronomia: Produção Vegetal, Universidade Federal do Piauí, 92 p., 2008.

CAMPIGLIA, M. A Influência de Sistemas Silvipastoris sobre a Dinâmica Populacional de Besouros Coprófagos. Dissertação de Mestrado em Agroecossistemas, Universidade Federal de Santa Catarina, 127 p., 2002.

CARVALHO, S.S. de. Escarabeídeos (Coleoptera: Scarabaeidae) em Três Diferentes Usos de Solo no Município de Nazária, Piauí, Brasil. Dissertação de Mestrado em Agronomia: Produção Vegetal, Universidade Federal do Piauí, 73 p., 2013.

COSTA, C. Coleoptera. In: JOLY, C.A.; BICUDO, C.E.M. (Org.). Biodiversidade do Estado de São Paulo, Brasil: síntese do conhecimento ao final do século XX. Invertebrados terrestres. São Paulo: Museu de Zoologia da Universidade de São Paulo, 1999.

COSTA, E.M.; ARAÚJO, E.L.; LOPES da SILVA, F.E.; NOGUEIRA, C.H.F.; SILVA, P.A.F. Diversidade de coleópteros em área cultivada com melancia no semiárido do rio grande do norte. Revista Agro@mbiente On-line, v. 8, n. 2, p. 293-297, 2014.

EMBRAPA. Sistema Brasileiro de Classificação de Solos. Rio de Janeiro: Embrapa Solos, 306 p., 2006.
FARIAS, R.R.S.; CASTRO, A.A.J.F. Fitossociologia de trechos da vegetação do Complexo Campo Maior, PI, Brasil. Acta. Bot. Bras., v. 18, n. 4., p. 949-963, 2004.

FAVILA, M.E.; G. HALFFTER. The use of indicator groups for measuring biodiversity as related to community structure and function. Acta Zoológica Mexicana, v. 72, n. 72, p. 125, 1997.

GALLO, D.; NAKANO, O.; SILVEIRA NETO, S.; CARVALHO, R.P.L.; BATISTA, G.C.; BERTI FILHO, E.; PARRA, J.R.P.; ZUCCHI, R.A.; ALVES, S.B.; VENDRAMIM, J.D.; MARCHINI, L.C.; LOPES, S.R.S.; OMOTO, C. et al. Entomologia Agrícola. Piracicaba: FEALQ, 920 p., 2002.

GOMES GONÇALVES, M.P. Relação entre tempo e besouros em mata de cocal. Rev. Bras. Meteorol., v. 32, n. 4, p. 543554, 2017.

GONÇALVES, T.T.; LOUZADA, J.N.C. Estratificação vertical de coleópteros carpófilos (Insecta: Coleoptera) em fragmentos florestais do sul do estado de Minas Gerais, Brasil. Ecol. austral, v. 15, n. 1, p. 101-110, 2005.

GULLAN, P.J.; CRASTON, P.S. Os Insetos: Um Resumo de Entomologia. Traduzido por Sonia Maria Marques Hoenen. São Paulo: Roca, 440 p., 2007.

HALFFTER, G. Historical and ecological factors determining the geographical distribution of beetles (Coleoptera: Scarabaeidae: Scarabaeinae). Folia Entomologica Mexicana, v. 15 , n. 82 , p. $195-238,1991$.

HALFFTER, G.; MATTHEWS, E.G. The natural history of dung beetles of the subfamily Scarabaeinae (Coleoptera: Scarabaeidae). Folia Entomológica Mexicana, n. 12-14, p. 1$312,1966$.

INSTITUTO BRASILEIRO DE GEOGRAFIA E ESTATÍSTICA (IBGE). Manual Técnico da Vegetação Brasileira. Série Manuais Técnicos em Geociências. n. 1. Rio de Janeiro: Ed. IBGE, 91 p., 1992.

KOLLER, W.W.; GOMES, A.; FLECHTMANN, C.A.H.; RODRIGUES, S.R.; BIANCHIN, I.; HONER, M.R. et al. Ocorrência e Sazonalidade de Besouros Copro/Necrófagos (Coleoptera; Scarabaeidae), em Massas Fecais de Bovinos, na Região de Cerrados do Mato Grosso do Sul. Campo Grande: EMBRAPA CNPGC, 1997.

LEXERØD, N.; EID, T. An evaluation of different diameter diversity indices based on criteria related to forest management planning. Forest Ecology and Management, v. 222, n. 2, p. 17-28, 2006.

MARINONI, R.C.; GANHO, N.G. Fauna de Coleoptera no Parque Estadual de Vila Velha, Ponta Grossa, Paraná, Brasil: abundância e riqueza das famílias capturadas através de armadilhas malaise. Rev. Bras. Zoologia, v. 20, n. 4, p. 737 744, 2003

MILLER JUNIOR, G. Tyler. Ciência Ambiental. São Paulo: Cengage Learning, 592 p., 2008.

MORAES, R.C.B.; HADDAD, M.L.; SILVEIRA NETO, S.; REYES, A.E.L. Software para análise faunística. In: Anais $8^{\circ}$ Simpósio de controle biológico. S. Pedro, p. 195, 2003.

NEVES, C.M.L. Análise da Vegetação e da Entomofauna de Coleópteros Ocorrentes em Fragmentos de Floresta Serrana de Brejo de Altitude no Estado da Paraíba. Dissertação de Mestrado Agronomia: Ecologia Vegetal e Meio Ambiente, Universidade Federal da Paraíba, 133 p., 2006. 
NICHOLS, E.; SPECTOR, S.; LOUZADA, J.; LARSEN, T.; AMEZQUITA, S.; FAVILA, M.E. et al. Ecological functions and ecosystem services provided by Scarabaeinae dung beetles. Biological Conservation, v. 141, n. 6, p. 1461-1474, 2008.

PAIVA, D.R. Escarabeíneos (Coleoptera: Scarabaeidae) Associados a Diferentes Sistemas de Manejo de Pastagens no Município de Teresina-PI. Dissertação de Mestrado em Agronomia: Produção Vegetal, Universidade Federal do Piauí, 56 p., 2009.

RODRIGUES, L.R.A. Os besouros coprófagos em pastagens. Anais do Simpósio sobre Ecossistema de Pastagens, p. 97-133, 1989.

RODRIGUES, W.C. Fatores que influenciam no Desenvolvimento dos insetos. Info Insetos, v. 1, n. 4, p. 1-4, 2004.

SANTOS FILHO, F.S.; ALMEIDA JR., E.B.; SOARES, C.J.R.S.; ZICKEL, C.S. Fisionomias das restingas do Delta do Parnaíba, Nordeste, Brasil. Revta. Bras. Geog. Física, v. 3, n. 3, p. 218-227, 2010.

SANTOS, S.R. de A. 2005. Diversidade de Coleoptera em um Fragmento de Mata Atlântica da Reserva Ecológica Gurjaú, Cabo de Santo Agostinho - PE. Dissertação de Mestrado em Ciências Biológicas: Biologia Animal, Universidade Federal de Pernambuco, 37 p., 2005.

SLADE, E.M.; MANN, D.J.; LEWIS, O.T. Biodiversity and ecosystem function of tropical forest dung beetles under contrasting logging regimes. Biological Conservation, v. 144, n. 1, p. 166-174, 2011.

THORNTHWAITE, C.W.; MATHER, J.R. The water balance. Publications in Climatology - Drexel Institute of Technology, v. 8, n. 1, p. 1-86, 1955.

License information: This is an open-access article distributed under the terms of the Creative Commons Attribution License (type CC-BY), which permits unrestricted use, distribution and reproduction in any medium, provided the original article is properly cited. 